\title{
Congenital fetal heart defect - an agreement between fetal echocardiography and autopsy findings
}

\author{
Jan Pavlicek ${ }^{\mathrm{a}, \mathrm{b}}$, Zdenek Tauber', Eva Klaskovad ${ }^{\mathrm{d}}$, Katerina Cizkova ${ }^{c}$, Martin Prochazka ${ }^{\mathrm{e}}$, Patricie Delongova ${ }^{\mathrm{f}}$, Beata Stefunko ${ }^{\mathrm{f}}$, \\ Iveta Szotkovska ${ }^{f}$, Jana Dvorackova ${ }^{f}$, Tomas Gruszka ${ }^{a}$
}

Aims. To determine the frequency of pregnancy terminations due to prenatal congenital heart defect (CHD) and assess the agreement fetal echocardiography (FECHO) and autopsy findings.

Methods. The data were retrospectively assessed between 2008 and 2017 in a population of 116698 live births. The correlations between the FECHO and autopsy findings were classified into five levels of agreement: complete, partial, altered diagnosis, disagreement, and unfeasible autopsy.

Results. Totally, 293 CHDs were identified and 49\% of families (143/293) decided to terminate the pregnancy. In $1 \%$ $(2 / 143)$ of cases, the autopsy could not be performed, for the other $99 \%(141 / 143)$, the pathologist confirmed the presence of CHDs. Complete agreement between FECHO and autopsy was achieved in 85\% (122/143). In 10\% (14/143) of cases, the pathologist found minor findings, which were not described in the FECHO. In 4\% (5/143) of cases, the pathologist changed the main diagnosis.

Conclusion. Altogether, the results indicated that $\mathrm{FECHO}$ is a highly sensitive method for the prenatal detection of $\mathrm{CHD}$ but is incapable of detecting the complete spectrum of cardiac defects. Autopsies verified the diagnosis, confirmed the overall impairment in the fetus, and provided data for further counselling of the affected family.

Key words: autopsy, fetal echocardiography, screening, termination of pregnancy, congenital heart defect, chromosomal aneuploidy

Received: March 16, 2019; Accepted: August 19, 2019; Available online: September 23, 2019

https://doi.org/10.5507/bp.2019.042

(c) 2020 The Authors; https://creativecommons.org/licenses/by/4.0/

${ }^{a}$ Department of Pediatrics and Prenatal Cardiology, University Hospital Ostrava, Ostrava, Czech Republic

${ }^{b}$ Biomedical Research Centre, University Hospital Hradec Kralove, Hradec Kralove, Czech Republic

'Department of Histology and Embryology, Faculty of Medicine and Dentistry, Palacky University Olomouc, Czech Republic

${ }^{d}$ Department of Pediatrics, University Hospital Olomouc and Faculty of Medicine and Dentistry, Palacky University Olomouc, Czech Republic ${ }^{e}$ Department of Medical Genetics, University Hospital Olomouc and Faculty of Medicine and Dentistry, Palacky University Olomouc, Czech Republic

fDepartment of Pathology, University Hospital Ostrava, Ostrava, Czech Republic

Corresponding author: Eva Klaskova, e-mail: klaskove@gmail.com

\section{INTRODUCTION}

Congenital heart defects (CHDs) are the most frequently observed morphological disorders in the population ${ }^{1}$. The incidence of CHD varies from 4 to 50 cases per 1000 live births, but when minor ventricular septal defects are also included, the incidence rises to 75 cases per 1000 live births ${ }^{2}$. Of the total number of CHDs, $35 \%$ are considered severe or critical, and most of these are prenatally detectable by fetal echocardiography (FECHO), which makes it possible to diagnose heart defects before birth ${ }^{3}$. All prenatally diagnosed CHDs require further assessment to identify extra-cardiac anomalies and genetic abnormalities. Definitive counselling should be performed at specialized centers.

In recent years, ultrasound techniques have developed rapidly and substantially. Prenatal CHD diagnostics have improved due to good prenatal screening organization and increasing physician experience. Some parents decide to terminate a pregnancy due to a diagnosed CHD. In any prenatal diagnostic setting, it is crucial to base a termination of pregnancy (TOP) on a correct fetal diagnosis, and it is important to perform a postmortem examination of the aborted fetus to confirm the cardiac and/or genetic impairment. A postmortem examination of an aborted fetus is an important tool to assess the quality and accuracy of the work performed by obstetric sonographers ${ }^{4}$.

At present, pathologists have an essential role in performing the autopsy and describing the heart defect in the fetus. This procedure might be difficult due to the small size of the heart, particularly in fetuses aborted during earlier weeks of pregnancy. The current trend in prenatal diagnostics is to screen during the first trimester of pregnancy and perform the heart autopsy between the $12^{\text {th }}$ and $14^{\text {th }}$ week. In a number of centers, the heart autopsy is performed as a biopsy without a precise description. Insufficient autopsies can distort the overall estimation of the incidence of all CHDs.

There are a lot of studies that have compared prenatal ultrasound observations of congenital anomalies with 
autopsy findings ${ }^{47}$, but this study is aimed at only heart defects and represents a pediatric cardiologist's view of prenatal screening for CHDs.

The aim of the present study was to describe the incidence of prenatally diagnosed CHDs and the frequency of TOPs due to a prenatal CHD diagnosis, and to assess how well ultrasound fetal heart examinations correlated to autopsy findings.

\section{METHODS}

\section{Study population}

This retrospective, cohort study was conducted between 2008 and 2017 in the Moravian-Silesian region of the northern part of Moravia in the Czech Republic. The present number of inhabitants is 1200000 , and this region has a stable birth rate of around 11500 births per year. During the monitored period, 116698 live births were registered in this area, and all pregnant women underwent FECHO by a gynecologist or pediatric cardiologist.

\section{Assessment of fetal heart}

Suspicious fetal cardiac pathology was referred to the Department of Pediatric and Prenatal Cardiology of the University Hospital Ostrava for FECHO and definitive counselling (Fig. 1). Only two physicians were responsible for fetal heart examinations and counselling during this study. The ultrasound examination was performed transabdominally. The echocardiograph ultrasound systems used were GE Vivid 7, Vivid 9, and Vivid 95e. These systems were equipped with trans multi-frequency wide-bandwidth transducers: C2-9 single crystal abdominal convex 2.3-8.4 MHz transducer, 6S phased-array 2.4-8.0 MHz transducer, 5S phased-array 3.0-9.0 MHz transducer, and M5Sc active matrix single crystal phased array 1.5-4.6 $\mathrm{MHz}$ transducer. The echocardiograph system provided basic 2D imaging, M-mode and Anatomical M-mode, Color Doppler imaging, and PW, CW Doppler imaging. For all cardiac defects, an ultrasonographic examination of extra-cardiac anomalies was performed by a specialist in obstetrics sonography, and all pregnant women were offered genetic counselling.

\section{Classification of cardiac abnormalities}

Complex cardiac abnormalities were classified according to the dominant heart lesion. In all complex heart lesions, an atrioventricular septal defect was a primary diagnostic lesion. A double outlet right ventricle was diagnosed if the aorta or pulmonary trunk over-rode the ventricular septal defect at over fifty percent. A single ventricle was classified as univentricular atrioventricular connection with double inlet or common atrioventricular valve. When an atrioventricular connection was absent, the diagnosis of either tricuspid or mitral atresia was established. Hypoplastic left heart syndrome was defined as a heart with a small left ventricle and flow reversal in the aortic arch. Coarctation of the aorta with ventricular septal defect was classified as coarctation of the aorta ${ }^{8,9}$.

\section{Termination of pregnancy and autopsy}

According to Czech legislation, parents have until the end of the $24^{\text {th }}$ week to decide whether to terminate a pregnancy after a CHD is prenatally detected. All TOPs due to CHDs were performed at the University Hospital Ostrava, and an autopsy was always performed in the presence of a pediatric cardiologist. Before the heart was removed from the fetus and examined, it was necessary to diagnose extra-cardiac malformations, identify the position of internal abdominal organs, and describe possible isomerisms ${ }^{10}$. The heart-lung block was always examined in the native state before fixation. Immediately after this initial examination, the heart was fixed in $4 \%$ buffered formaldehyde for at least $24 \mathrm{~h}$. The original protocol for the fetal heart autopsy included incisions at the base and apex and longitudinal incisions of the ventricles and outflow tracts ${ }^{6}$. When the heart was too small (under the $16^{\text {th }}$ week), we used continuous transverse sections of the whole fixed preparation. The examination always concluded with photographic documentation and a comparison with ultrasonography (USG) findings. Correlations between the FECHO and autopsy findings were classified into five levels (categories 1-5) of agreement, according to a modification of the method described in previous studies that compared prenatal diagnostics with fetal autopsy findings $\left.{ }^{11,12}: 1\right)$ full agreement between the ultrasound and autopsy when the FECHO exactly matched the autopsy findings; 2) partial agreement with a missed abnormality when a dominant heart lesion was confirmed but the pathologist identified minor findings associated with complex CHDs (e.g., a ventricular defect, stenoses in great arteries, aortic coarctation); 3) altered diagnosis when the pathologist changed the original diagnosis but preserved the CHD severity (e.g., common arterial trunk vs. pulmonary atresia with a ventricular septal defect; tetralogy of Fallot vs. double outlet right ventricle; single ventricle vs. hypoplasia of the left or right ventricle); 4) disagreement when the findings suspected during the ultrasound examination were not detected at autopsy, and the pathologist did not confirm the suspected CHD based on the FECHO; 5) unfeasible autopsy with inability to perform the autopsy due to autolysis or fragmentation of the fetus after the abortion.

\section{Statistical analysis}

All data were stored and processed with Microsoft Excel. The results are expressed in terms of absolute and relative frequencies. The chi-square test was used to evaluate other comparisons. The level of significance $(\alpha)$ for type I errors ( $P$-value) was set at the level of 0.05 . Statistical tests were performed with IBM SPSS software, v. 24.

\section{RESULTS}

A total of 293 CHDs were prenatally diagnosed in the population of 116698 live births between 2008 and 2017 (i.e., 2.5 cases/1000 live births). In the prenatal period, 


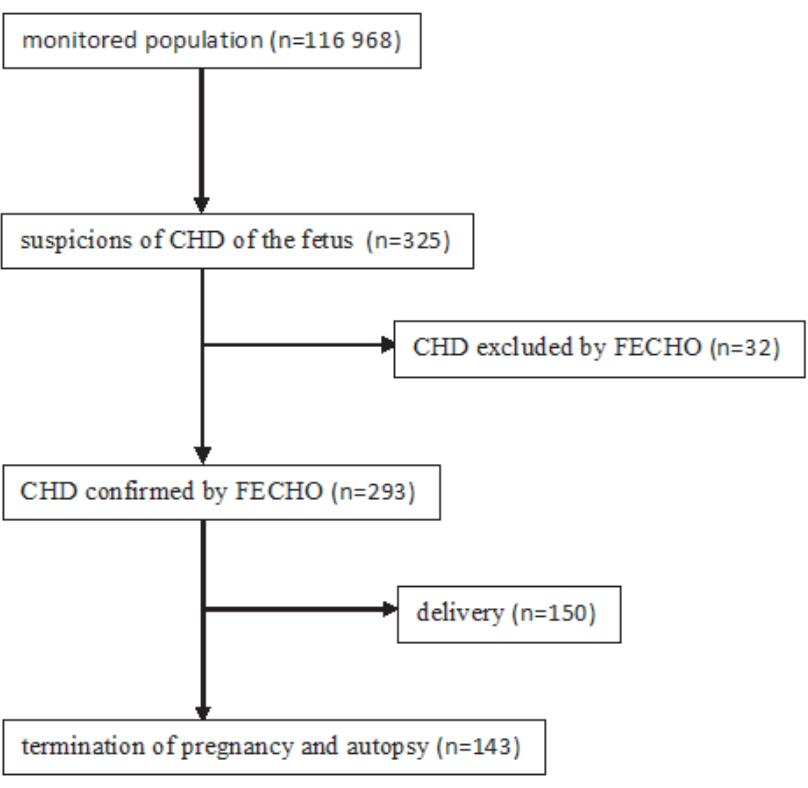

Fig. 1. Flow chart of recruitment of fetuses in the study.

CHDs were diagnosed at a gestational age between the $12^{\text {th }}$ and $28^{\text {th }}$ week of pregnancy (median of the $21^{\text {st }}$ week). Only 7\% (21/293) of CHDs were detected in the first trimester. Among all the prenatally diagnosed CHDs, $68 \%$ (200/293) were isolated impairments, 24\% (69/293) were genetically associated impairments, and 8\% (24/293) were extra-cardiac morphological pathologies, with no genetic anomaly (Table 1). Among the genetic impairments, $80 \%$ of the karyotype anomalies were trisomy chromosomal disorders (trisomy 21, 18, 13) and chromosome 22q11 deletions (DiGeorge syndrome). The most frequently observed morphological impairments were gastrointesti- nal tract and urogenital tract defects or limb deformities. Table 2 gives a detailed listing of CHDs in relation to individual genetic and extra-cardiac abnormalities.

Upon learning of a prenatal CHD diagnosis, 49\% (143/293) of families decided to undergo a TOP (Table 1). During the study, the week at which a pregnancy was interrupted showed a decrease, but the average number of terminations did not change (Fig. 2, 3). The frequency of TOPs was lower in the group of fetuses with isolated CHDs than in the group with confirmed genetic pathologies associated with the CHD, and also lower in the group that had CHDs with a morphological anomaly and normal karyotype (38\% [76/200] vs. $74 \%$ [51/69] and vs. $64 \%$ [16/24], respectively; $P<0.0001)$.

All the fetuses were examined by a pathologist after the TOP. In $1 \%(2 / 143)$ of cases, it was not possible to perform the autopsy due to autolysis or fragmentation of the fetus (category 5). For the other 99\% (141/143) of cases, the pathologist was able to examine the heart for defects (categories 1-3). We did not observe any TOP decisions based on false-positive FECHO findings, where the autopsy showed a normal heart anatomy (category 4). The pathologist's description of the fetuses that were terminated because of a CHD diagnosis differed in part from the previous FECHO. Complete agreement (category 1) between FECHO and the autopsy was achieved in $85 \%(122 / 143)$ of cases. In $10 \%(14 / 143)$ of cases, the pathologist found minor findings associated with complex CHDs, which were not described in the FECHO, but a major heart defect was confirmed (category 2). The most frequent supplementary findings were a pathology of the aortic arch (aortic coarctation in 5 cases, interruption of the aortic arch in 2 cases) and ventricular septal defect ( 3 cases). In $4 \%(5 / 143)$ of cases (all cases in the second trimester), the pathologist changed the main diagnosis

Table 1. Prenatally diagnosed congenital heart defects, associated anomalies, and rate of termination of pregnancy.

\begin{tabular}{|c|c|c|c|c|c|}
\hline $\begin{array}{l}\text { Congenital heart defect } \\
\text { (fetal diagnosis) }\end{array}$ & & Isolated & $\begin{array}{c}\text { Genetic } \\
\text { abnormalities } \\
\text { n (\%) }\end{array}$ & $\begin{array}{c}\text { Extracardiac } \\
\text { abnormalities } \\
\text { with normal karyotype } \\
\mathrm{n}(\%)\end{array}$ & $\begin{array}{c}\text { Termination } \\
\text { of pregnancy } \\
\mathrm{n}(\%)\end{array}$ \\
\hline Transposition of great ariteries & $(n=26)$ & $23(88)$ & $1(4)$ & $2(8)$ & $6(23)$ \\
\hline Corrected transposition of great arteries & $(n=3)$ & $2(67)$ & 0 & $1(33)$ & $2(67)$ \\
\hline Tetralogy of Fallot & $(n=31)$ & $16(52)$ & $13(42)$ & $2(6)$ & $15(48)$ \\
\hline Double outlet right ventricle & $(n=12)$ & $10(83)$ & $2(17)$ & 0 & $6(50)$ \\
\hline Hypoplastic left heart syndrome & $(n=43)$ & $33(76)$ & $5(12)$ & $5(12)$ & $35(81)$ \\
\hline Interruption of the aortic arch & $(n=1)$ & $1(100)$ & 0 & 0 & $1(100)$ \\
\hline Coarctation of aorta & $(n=15)$ & $12(80)$ & $1(7)$ & $2(13)$ & $1(7)$ \\
\hline Atrioventricular septal defect & $(n=46)$ & $15(32)$ & $27(59)$ & $4(9)$ & $30(65)$ \\
\hline Ventricular septal defect & $(n=29)$ & $18(62)$ & $9(31)$ & $2(7)$ & $4(14)$ \\
\hline Tricuspid atresia & $(n=8)$ & $7(87)$ & $1(13)$ & 0 & $7(87)$ \\
\hline Pulmonary atresia/ intact ventricular septum & $(n=7)$ & $4(57)$ & 0 & $3(43)$ & $7(100)$ \\
\hline Pulmonary atresia/ventricular septal defect & $(n=8)$ & $6(75)$ & $2(25)$ & 0 & $6(75)$ \\
\hline Aortic stenosis & $(\mathrm{n}=21)$ & $19(90)$ & $2(10)$ & 0 & $8(38)$ \\
\hline Pulmonary stenosis & $(n=22)$ & $19(86)$ & $2(9)$ & $1(5)$ & $2(9)$ \\
\hline Single ventricle & $(n=7)$ & $5(72)$ & $1(14)$ & $1(14)$ & $4(57)$ \\
\hline Common arterial trunk & $(n=8)$ & $4(50)$ & $3(38)$ & $1(12)$ & $8(100)$ \\
\hline Ebstein's anomaly & $(n=6)$ & $6(100)$ & 0 & 0 & $1(17)$ \\
\hline Total & $(n=293)$ & $200(68)$ & $69(24)$ & $24(8)$ & $143(49)$ \\
\hline
\end{tabular}


Table 2. Detailed listing of the association between CHDs and genetic and morphological impairments.

\begin{tabular}{|c|c|c|}
\hline $\begin{array}{l}\text { Congenital heart defect } \\
\text { (fetal diagnosis) }\end{array}$ & Genetic abnormalities & $\begin{array}{l}\text { Extracardiac abnormalities } \\
\text { with normal karyotype }\end{array}$ \\
\hline Transposition of great arteries & Trisomy $18(\mathrm{n}=1)$ & $\begin{array}{l}\text { hypoplastic left lung }(n=1) \\
\text { genital malformation }(n=1)\end{array}$ \\
\hline $\begin{array}{l}\text { Corrected transposition of great } \\
\text { arteries }\end{array}$ & 0 & situm viscerum inversus $(n=1)$ \\
\hline Tetralogy of Fallot & $\begin{array}{l}\text { Trisomy } 21(\mathrm{n}=4) \\
\text { Deletion } 22 \mathrm{q} 11.2(\mathrm{n}=2) \\
\text { Noonan sy }(\mathrm{n}=2) \\
\text { Trisomy } 18(\mathrm{n}=1) \\
47 \mathrm{XX}+9(\mathrm{n}=1) \\
47 \mathrm{XX}+\text { mar, redundancy } 12 \text { and } 20(\mathrm{n}=1) \\
46 \mathrm{XY} \text {, del }(4) \mathrm{t}(4,4)(\mathrm{p} 16.2 \mathrm{q} 31.22)(\mathrm{n}=1) \\
47 \mathrm{XX}+22(5)(\mathrm{n}=1)\end{array}$ & $\begin{array}{l}\text { atresia ani, genital malformation }(n=1) \\
\text { hypoplasia of the radius }(n=1)\end{array}$ \\
\hline Double outlet right ventricle & $\begin{array}{l}\text { Trisomy } 13(n=1) \\
\text { Trisomy } 21(n=1)\end{array}$ & 0 \\
\hline Hypoplastic left heart syndrome & $\begin{array}{l}\text { Monosomy } \mathrm{X}(\mathrm{n}=2) \\
\text { Deletion 22q11.2 }(\mathrm{n}=1) \\
\text { Trisomy } 18(\mathrm{n}=1) \\
\text { Translocation }(13 / 14)(\mathrm{n}=1)\end{array}$ & $\begin{array}{l}\text { hypoplastic left lung }(n=1) \\
\text { hypoplastic right lung, genital malformation } \\
(n=1) \\
\text { situm viscerum inversus }(n=1) \\
\text { gastrointestinal malformations }(n=1) \\
\text { ren arcuatus }(n=1)\end{array}$ \\
\hline Interruption of the aortic arch & 0 & 0 \\
\hline Coarctation of aorta & Cri du chat syndrome $(\mathrm{n}=1)$ & $\begin{array}{l}\text { agenesis of the left kidney, multicystic } \\
\text { dysplasia of the right kidney }(n=1) \\
\text { diaphragmatic hernia }(n=1)\end{array}$ \\
\hline Atrioventricular septal defect & $\begin{array}{l}\text { Trisomy } 21(\mathrm{n}=22) \\
\text { Trisomy } 18(\mathrm{n}=3) \\
\text { Trisomy } 13(\mathrm{n}=1) \\
\text { Opitz syndrome }(\mathrm{n}=1)\end{array}$ & $\begin{array}{l}\text { right or left isomerism }(n=2) \\
\text { esophageal atresia }(n=1) \\
\text { hygroma colli cysticum }(n=1)\end{array}$ \\
\hline Ventricular septal defect & $\begin{array}{l}\text { Trisomy } 18(n=3) \\
\text { Trisomy } 13(n=2) \\
\text { Deletion } 22 q 11.2(n=2) \\
\text { Trisomy } 21(n=1) \\
\text { Smith Magenis syndrome }(n=1)\end{array}$ & $\begin{array}{l}\text { limb defect }(n=1) \\
\text { cheilognathopalatoshisis }(n=1)\end{array}$ \\
\hline Tricuspid atresia & Monosomy X ( $\mathrm{n}=1)$ & 0 \\
\hline $\begin{array}{l}\text { Pulmonary atresia/ intact } \\
\text { ventricular septum }\end{array}$ & 0 & $\begin{array}{l}\text { left isomerism }(n=1) \\
\text { situm viscerum inversus }(n=1) \\
\text { spina bifida }(n=1)\end{array}$ \\
\hline $\begin{array}{l}\text { Pulmonary atresia/ventricular } \\
\text { septal defect }\end{array}$ & Deletion $22 \mathrm{q} 11.2(\mathrm{n}=2)$ & 0 \\
\hline Aortic stenosis & $\begin{array}{l}\text { Monosomy } X(n=1) \\
\text { Trisomy } 13(n=1)\end{array}$ & 0 \\
\hline Pulmonary stenosis & $\begin{array}{l}\text { Monosomy X }(n=1) \\
\text { CHARGE syndrome }(n=1)\end{array}$ & lung hypoplasia $(\mathrm{n}=1)$ \\
\hline Single ventricle & Trisomy $18(n=1)$ & right isomerism $(\mathrm{n}=1)$ \\
\hline Common arterial trunk & $\begin{array}{l}\text { Trisomy } 13(n=2) \\
\text { Partial deletion of the short arm of } \\
\text { chromosome } 13(n=1)\end{array}$ & hydronephrosis $(\mathrm{n}=1)$ \\
\hline Ebstein's anomaly & 0 & 0 \\
\hline
\end{tabular}


Table 3. Diagnoses that differed between the fetal echocardiography and autopsy.

\begin{tabular}{|c|c|c|}
\hline Terminated congenital heart defect & Missed abnormalities & Altered diagnosis \\
\hline Transposition of grat arteries & ventricular septal defect $(n=1)$ & double outlet right ventricle $(\mathrm{n}=1)$ \\
\hline Tetralogy of Fallot & $\begin{array}{l}\text { pulmonary atresia, extremely form of } \\
\text { Tetralogy of Fallot }(n=1)\end{array}$ & \\
\hline Hypoplastic left heart syndrome & ventricular septal defect $(n=1)$ & \\
\hline Coarctation of aorta & & interruption of the aortic $\operatorname{arch}(n=1)$ \\
\hline Atrioventricular septal defect & $\begin{array}{l}\text { coarctation of aorta }(n=2) \\
\text { double outlet right ventricle }(n=1) \\
\text { aortic stenosis }(n=1) \\
\text { pulmonary stenosis }(n=1)\end{array}$ & \\
\hline Ventricular septal defect & coarctation of aorta $(n=1)$ & \\
\hline Tricuspid atresia & ventricular septal defect $(n=1)$ & \\
\hline $\begin{array}{l}\text { Pulmonary atresia/ventricular septal } \\
\text { defect }\end{array}$ & & common arterial trunk $(\mathrm{n}=1)$ \\
\hline Aortic stenosis & coarctation of aorta $(n=2)$ & \\
\hline Single ventricle & & $\begin{array}{l}\text { double outlet right ventricle with } \\
\text { hypoplastic left ventricle and malposition } \\
\text { of the great arteries }(n=1)\end{array}$ \\
\hline Common arterial trunk & interruption of the aortic arch $(n=2)$ & $\begin{array}{l}\text { pulmonary atresia with ventricular septal } \\
\text { defect }(n=1)\end{array}$ \\
\hline
\end{tabular}

(category 3 ) but preserved its severity and complex character. Missed abnormalities and altered diagnoses are listed in Table 3.

\section{DISCUSSION}

Most CHDs can be prenatally detected, and the overall success of prenatal CHD diagnoses has generally improved $^{13}$. FECHO has displayed high sensitivity and specificity for detecting major CHDs ( ref. $^{14}$ ). The main purpose of prenatal diagnosis of CHDs is to detect critical defects that are life-threatening for the child and to diagnose complex heart disease that can significantly affect morbidity and mortality in patients ${ }^{15}$. However, some parents do not continue the pregnancy and decide to terminate.

The main findings of this study are as follows: $i$ ) half of parents decided to undergo a TOP when a CHD was found; ii) there was complete agreement between FECHO and autopsy findings in $85 \%$ of cases; iii) the pathologist supplemented the unidentified minor cardiac anomalies or changed the main diagnosis in $14 \%$ of cases; iv) disagreement between the FECHO and autopsy (false-positive FECHO and normal heart anatomy) was not found.

According to Czech legislation, parents are given until the end of the $24^{\text {th }}$ week to decide whether to undergo a TOP after a CHD is prenatally detected. The parents' decision-making process is influenced by the severity of the CHD, the mother's age, and the associated anoma- $\operatorname{lies}^{13,16,17}$. The rates of TOPs due to diagnoses vary significantly in the published studies from 0 to $50 \%$ (ref. ${ }^{18}$ ). In our study, $49 \%$ of families decided to undergo a TOP when a CHD was diagnosed, and therefore, the incidence of TOPs in our study region was among the highest in the world. The reason for this high rate of TOPs could be the fact that the monitored area is a strong industrial area with lower economic power, higher unemployment, worse social conditions, and low level of religious beliefs. Currently, CHD screening can be performed in the first trimester, and this has significantly impacted the spectrum of detected CHDs and the outcome of pregnancy. The vast majority of major CHDs can be detected during the first trimester by experienced fetal sonographers and obstetricians ${ }^{19}$. However, the authors still prefer to diagnose CHD in the second trimester between the $18^{\text {th }}$ and $22^{\text {nd }}$ week of pregnancy, because that is when the highest diagnosis rate and the most detailed analysis of heart anatomy can be achieved ${ }^{20}$. In cases of high-risk pregnancies, early fetal diagnostics are feasible ${ }^{21-23}$. In our study region and similar to the rest of the world, the time frame for performing prenatal diagnostics has shifted to an earlier time frame during pregnancy but still remains in the second trimester. Despite the reported increase in the number of TOPs in early diagnosis ${ }^{9,24}$, the TOP average did not change fundamentally in our study.

Compared to postnatal CHD diagnoses, prenatal CHD diagnoses include a higher incidence of chromosomal anomalies ${ }^{25}$. In our prenatal patient cohort, the majority of CHDs were isolated impairments. A multi- 


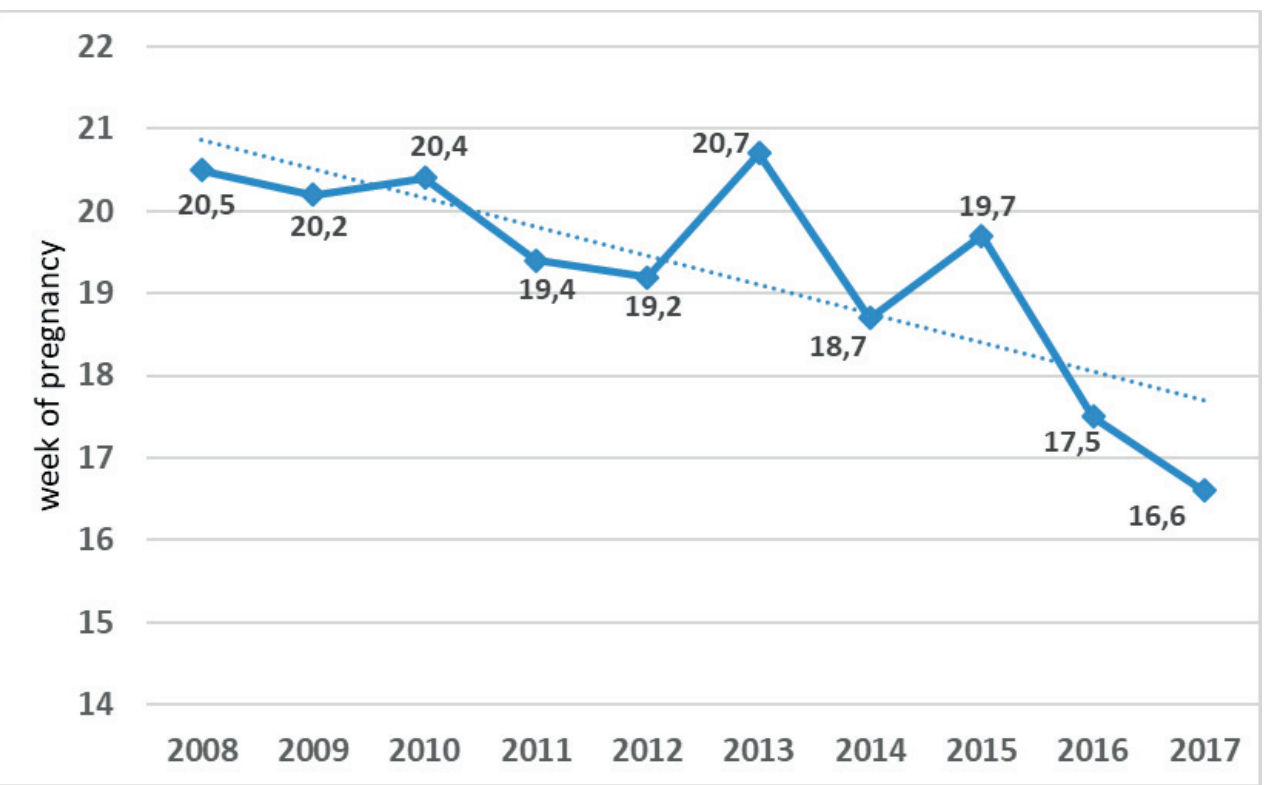

Fig. 2. Average week of termination of pregnancy.

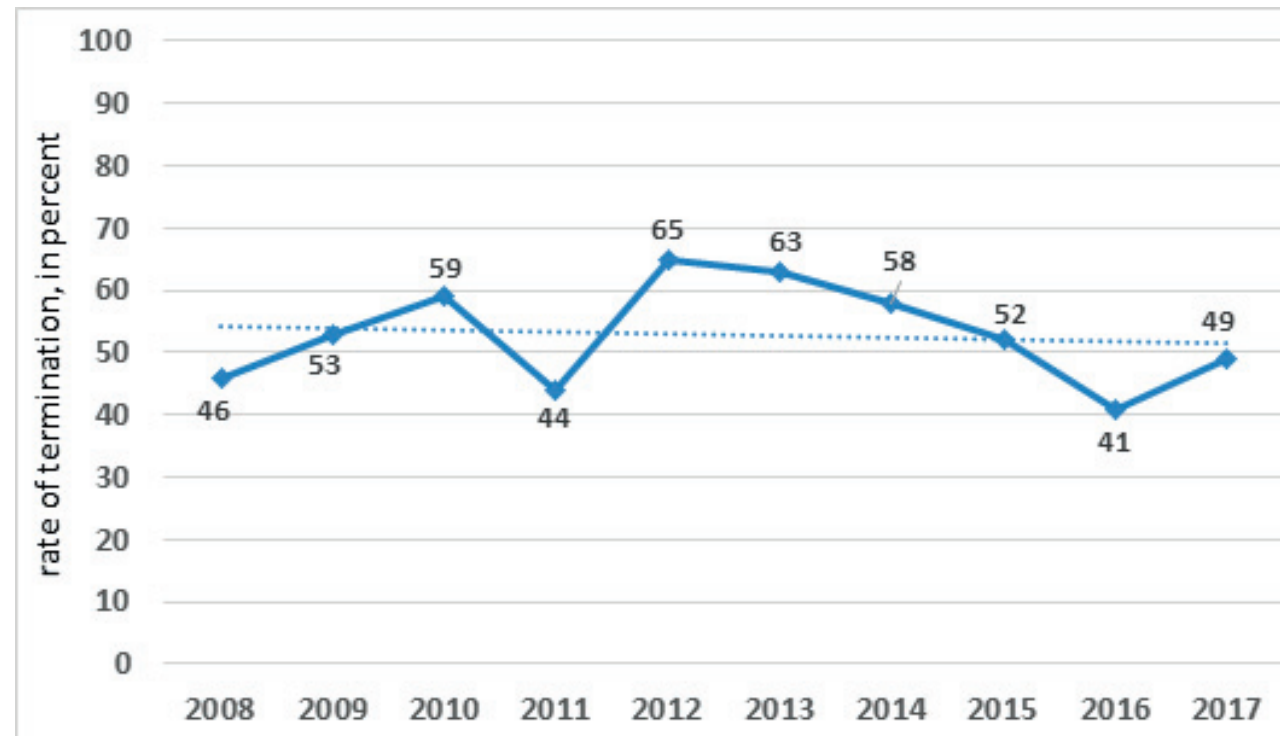

Fig. 3. Rate of termination of pregnancy.

factorial hypothesis still plays a leading role in etiology, but approximately 20-25\% of CHDs are associated with a precise genetic cause ${ }^{26}$. This corresponds to the findings in our study that showed $24 \%$ of the CHDs had associated genetic pathologies. Trisomies of chromosomes 21,18 , and 13 were responsible for most of the genetic abnormalities $^{27,28}$. Down syndrome had the highest frequency and was associated with atrioventricular septal defects, the high risk of genetic abnormalities is associated with conotruncal defects ${ }^{29,30}$. The total occurrence of extra-cardiac anomalies was $32 \%$, similar to that in previous studies $^{30,31}$. In our study, the tendency for a TOP was higher when a CHD was diagnosed with the presence of extra-cardiac anomalies than when the CHD was isolated. Generally speaking, the presence of other anomalies has a negative impact on the prognosis of the fetus; thus, it is necessary to perform a complex examination of the pregnancy.
It is well known that in cases of complex fetal malformations, an autopsy can contribute up to one-third of the pathological information needed for a diagnosis ${ }^{32}$. Thus, one of the main aims of the present study was to determine the correlations between prenatal and postnatal findings. In our study, the fetal heart defect was always confirmed by a pathologist. The previous study found a full agreement between the FECHO and autopsy findings in $70-80 \%$ of cases $^{33-35}$. We found that $85 \%$ of cases showed a full agreement between the FECHO and autopsy findings. In other studies, partial agreement (e.g., disagreement in the specific findings but agreement on the main diagnosis) occurred in up to $91 \%$ of cases $^{34}$. In our study, this rate was slightly higher (95\%). The most frequent additional findings provided by the pathologist were pathology of the aortic arch and a ventricular septal defect. The ventricular septal defect frequently occurs in the muscular part of the heart but does not typically 
manifest hemodynamically in the fetus; thus, its fetal diagnosis usually requires the Doppler technique ${ }^{36}$. Similarly, an aortic coarctation is not diagnosed with routine screening due to fetal hemodynamics and flow through arterial ducts. Nevertheless, it is a potentially life-threatening postnatal condition ${ }^{37}$.

In five cases ( $4 \%$ of the cohort), the pathologist changed the diagnosis but preserved the significance of the heart defect. In two of these five cases, the diagnosis was changed from a persisting arterial trunk to pulmonary atresia with a ventricular septal defect. An examination of the conditions in the area of the arterial duct and thoracic aorta during FECHO is necessary, and the diagnosis may be further specified with the use of 4D-ultrasound techniques $^{38}$. In one of the five cases, the diagnosis of a single ventricle was changed to a definite hypoplastic left ventricle with a double outlet right ventricle. We did not detect the left ventricle in this obese patient, and we also did not recognize the interruption of the aortic arch and the coarctation. Therefore, body mass index of the mother is a significant factor in fetal investigation. The ability to view these anatomic structures is affected even in mild and moderate obesity. We agree that the optimal timing of the initial examination for obese women, in order to maximize the efficiency with respect to the potential duration of the scan and the need for a repeat scan, appears to be 18-20 weeks ${ }^{39}$. In one case, the autopsy indicated the branching of large arteries in a fetus that had been diagnosed with a transposition of the great arteries with a ventricular septal defect and a double outlet right ventricle. In that case, the position of the aorta above the septal defect determined the final diagnosis, and therefore, the pathologist's findings differed from the ultrasonography findings.

Generally, the published frequency of disagreement between the prenatal diagnosis and autopsy is very low (9\%). Only $4 \%$ of ultrasound findings were not confirmed during the autopsy, and $5 \%$ of autopsy findings were not observed during the $\mathrm{USG}^{33}$. In the present study, we did not encounter any false-positive diagnoses based on the USG, and the pathological findings that were observed in the heart FECHOs were always associated with a heart defect confirmed by the pathologist, albeit sometimes a different type of defect. A total of two (1\%) fetuses could not be further examined due to autolysis or fragmentation. The number of unfeasible autopsies was similar to the rates reported in other published series ${ }^{33}$, and we considered this an acceptable result.

In summary, the autopsies confirmed or broadened the ante-mortem findings, enabled the diagnoses of pathologies that were not diagnosed with USG prior to the TOP, and provided further information for pre-conception care. This information was used in discussing the possibilities of recurrence and consequences for other family members ${ }^{4,40}$. The final CHD diagnosis was always determined after the autopsy, and therefore, the autopsy is important for further medical research, statistical analyses, and maintaining the standard of care ${ }^{41}$. The autopsy quality and definitive conclusions were influenced by the size of the fetus and the experience of the pathologist ${ }^{42,43}$.
During the study, the week at which a pregnancy was interrupted showed a decrease and we found that when the heart is too small, it is possible to conduct the autopsy using transverse cuts and that this method also has the possibility of very good interpretation. Some CHDs were not identified during the FECHO and the pathologist supplemented the findings of these abnormalities. The most common were defects in the conotruncal region and the aortic arch. FECHO needs to be more carefully performed when investigating these parts of the fetal heart.

In our experience, we have emphasized cooperation between the pathologist and the pediatric cardiologist. Indeed, consultations have proven beneficial regarding ultrasound findings, determinations of expected diagnoses, and proposals of autopsy procedures.

The advantages of the present study were the precise knowledge regarding the prenatally diagnosed CHDs in the observed population, and the tight cooperation between the pathologists and pediatric cardiologists. A potential drawback of the study was that we only studied prenatally detected CHDs. However, we consider this sufficient for the purpose and sense of prenatal care and for addressing the aims of this study. There are some missing data in this study. For example, CHD might not have been identified by the sonographer when the pregnancy was primarily terminated due to the presence of the significant extra-cardiac fetal pathology or the defect was not described by a pathologist at another workplace.

\section{CONCLUSION}

In conclusion, our results indicate that FECHO is a highly sensitive method for prenatal detection of CHD but is incapable of detecting the complete spectrum of cardiac defects. Autopsies verified the diagnosis, confirmed the overall impairment in the fetus, and provided data for further counselling of the affected family. Cooperation between the prenatal diagnostician and the pathologist was shown to be essential.

Acknowledgement: Supported by Ministry of Health of the Czech Republic - conceptual development of research organization (FNO1, 0098892). Additional support came from the Faculty Hospital in Hradec Kralove (a long-term organization development plan). The authors would like to thank the Department of Pediatrics and the Department of Pathology of the Ostrava Municipal Hospital for their long-term cooperation.

Author contributions: JP: data collection, manuscript writing, responsible for pregnant women's diagnostics and treatment; EK: data interpretation, final approval; TG: pregnant women's diagnostics and treatment; MP: genetic consultation, data interpretation; ZT, KC, PD, BS, IS: data interpretation.

Conflict of interest statement: The authors state that there are no conflicts of interest regarding the publication of this article. 


\section{REFERENCES}

1. van der Linde $D$, Konings $E E$, Slager MA, Witsenburg M, Helbing WA Takkenberg JJ, Roos-Hesselink JW. Birth prevalence of congenital heart disease worldwide. J Am Coll Cardiol 2011;58:2241-2247.

2. Hoffman Jl, Kaplan S. The incidence of congenital heart disease. J Am Coll Cardiol 2002;39:1890-900.

3. Nayak K, Naveen Chandra GS, Shetty R, Narayan PK. Evaluation of fetal echocardiography as a routine antenatal screening tool for detection of congenital heart disease. Cardiovasc Diagn Ther 2016;6:44.

4. Kaasen A, Tuveng J, Heiberg A, Scott H, Haugen G. Correlation between prenatal ultrasound and autopsy findings: a study of second trimester abortions. Ultrasound Obstet Gynecol 2006; 28: 925-33.

5. Boyd PA, Tondi F, Hicks NR, Chamberlain PF. Autopsy after termination of pregnancy for fetal anomaly: retrospective cohort study. Brit Med J 2004;328:137.

6. Laussel-Riera A, Devisme L, Manouvrier-Hanu S, Puech F, Robert Y, Gosselin B. Value of fetopathological examination in medical abortions: comparison of prenatal diagnosis and autopsy results of 300 fetuses. In Annales de pathologie. Ann Pathol 2000;20:549-57.

7. Isaksen CV, Eik Nes SH, Blaas HG, Torp SH. Fetuses and infants with congenital urinary system anomalies: correlation between prenata ultrasound and postmortem findings. Ultrasound Obstet Gynecol 2000;15:177-85.

8. Marek J, Tomek V, Škovránek J, Povýšilová V, Šamánek M. Prenatal ultrasound screening of congenital heart disease in an unselected national population: a 21-year experience. Heart 2011;97:124-30.

9. Jicinska H, Vlasin P, Jicinsky M, Grochova I, Tomek V, Volaufova J, Skovranek J, Marek J. Does First-Trimester Screening Modify the Natural History of Congenital Heart Disease? Circulation 2017;135:1045-55

10. Bove KE. Autopsy Committee of the College of American Pathologists. Practice guidelines for autopsy pathology: the perinatal and pediatric autopsy. Arch Pathol Lab Med 1997;121:368.

11. Donnelly $\mathbf{W H}$, Hawkins $\mathrm{H}$. Optimal examination of the normally formed perinatal heart. Hum Pathol 1987;18:55-60.

12. Amini $\mathrm{H}$, Antonsson P, Papadogiannakis N, Ericson $\mathrm{K}$, Pilo Ch, Eriksson $\mathrm{L}$, Westgren $\mathrm{M}$, Axelsson O. Comparison of ultrasound and autopsy findings in pregnancies terminated due to fetal anomalies. Acta Obstet Gyn Scan 2006;85:1208-16.

13. Cannie M, Votino C, Moerman PH, Vanheste R, Segers V, Van Berkel K, Hanssens M, Kang X, Cos T, Kir M, Balepa L, Divano L, Foulon W, De Mey J, Jani J. Acceptance, reliability and confidence of diagnosis of fetal and neonatal virtuopsy compared with conventional autopsy: a prospective study. Ultrasound Obstet Gynecol 2012;39:659-65.

14. Chu C, Yan Y, Ren Y, Li X, Gui Y. Prenatal diagnosis of congenital heart diseases by fetal echocardiography in second trimester: a Chinese multicenter study. Acta Obstet Gyn Scan 2017;96:454-63.

15. Tomek V, Gilík J, Jičínska H, Pavlíček J, Navrátil J, Čutka D, Vlašín $P_{\text {, }}$ Lacinová M, Marek J, Škovránek J. Prenatal detection of congenita heart defects and its consequences. Čes-slov Pediat 2018;73:284-90.

16. Chenni N, Lacroze V, Pouet C, Fraisse A, Kreitmann B, Gamerre M, Boubli L, D'Ercole C. Fetal heart disease and interruption of pregnancy: factors influencing the parental decision-making process. Prenat diagn 2012;32:168-72.

17. De Groote K, Vanhie E, Roets E, Ramaekers P, De Wilde H, Panzer J, Vandekerckhove K, Bove T, François K, Van Herck K, De Wolf D. Outcome after prenatal and postnatal diagnosis of complex congenital heart defects and the influence of genetic anomalies. Prenat diagn 2017;37:983-91.

18. Garne E, Stoll C, Clementi M. Evaluation of prenatal diagnosis of congenital heart diseases by ultrasound: experience from 20 European registries. Ultrasound Obstet Gynecol 2001;17:386-91.

19. Persico N, Moratalla J, Lombardi CM, Zidere V, Allan L, Nicolaides KH. Fetal echocardiography at 11-13 weeks by transabdominal highfrequency ultrasound. Ultrasound Obstet Gynecol 2011;37:296-301.

20. Campbell S, Allan L, Benacerraf B, Copel JA, Carvalho JS, Chaoui R. Isolated major congenital heart disease. Ultrasound Obstet Gynecol 2001;17:370-9.

21. ACOG Committee on Practice Bulletins. AGOG practice bulletin No 58. Ultrasonography in pregnancy. Obstet Gynecol 2004;58:1449-58.

22. Bellotti M, Fesslova V, De Gasperi C, Rognoni G, Bee V, Zucca I, Lombardi CM. Reliability of the first trimester cardiac scan by ultrasound trained obstetricians with high frequency transabdominal probes in foetuses with increased nuchal translucency. Ultrasound Obst Gyn 2010;36:272-8.

23. Comas GC, Galindo A, Martinez JM, Carrera JM, Gutiérrez-Larraya F, de la Fuente P, Puerto B, Borrell A. Early prenatal diagnosis of major cardiac anomalies in a high risk population. Prenat diagn 2002;22:586-93.

24. Brick DH, Allan LD. Outcome of prenatally diagnosed congenital heart disease: an update. Pediatr Cardiol. 2002;23:449-53.

25. Allan LD, Sharland GK, Milburn A, Lockhart SM, Groves AMM, Anderson $\mathrm{RH}$, Cook AC, Nuala LK. Prospective diagnosis of 1,006 consecutive cases of congenital heart disease in the fetus. J Am Coll Cardiol 1994;23:1452-8.

26. Blue GM, Kirk EP, Sholler GF, Harvey RP, Winlaw DS. Congenital heart disease: current knowledge about causes and inheritance. Med J Australia 2012;197:155-9.

27. Calzolari E, Garani G, Cocchi G, Magnani C, Rivieri F, Neville A, Astolfi G, Baroncini A, Garavelli L, Gualandi F, Scorrano M, Bosi G. Congenital heart defects: 15 years of experience of the Emilia-Romagna Registry (Italy). Eur J Epidemiol 2003;18:773-80.

28. Bell R, Rankin J, Donaldson LJ. Down's syndrome: occurrence and outcome in the north of England, 1985-99. Paediatr Perinat Ep 2003;17:33-9.

29. Tumanyan MR, Filaretova OV, Chechneva V, Gulasaryan RS, Butrim IV, Bockeria LA. Repair of complete atrioventricular septal defect in infants with Down syndrome: outcomes and long-term results. Pediatr cardiol 2015;36:71-5.

30. Song MS, Hu A, Dyhamenahali U, Chitayat D, Winsor EJT, Ryan G, Smallhorn J, Barrett J, Yoo SJ, Hornberger LK. Extracardiac lesions and chromosomal abnormalities associated with major fetal heart defects: comparison of intrauterine, postnatal and postmortem diagnoses. Ultrasound Obstet Gynecol 2009;33:552-9.

31. Dadvand P, Rankin J, Shirley MD, Rushton S, Mulloli TP. Descriptive epidemiology of congenital heart disease in Northern England. Paediatr Perinat Ep 2009;23:58-65.

32. Sankar VH, Phadke SR. Clinical utility of fetal autopsy and comparison with prenatal ultrasound findings. J Perinatol 2006;26:224.

33. Rossi AC, Prefumo F. Correlation between fetal autopsy and prenatal diagnosis by ultrasound: A systematic review. Eur J Obstet Gyn R B 2017;210:201-6.

34. Isaksen CV, Eik-Nes SH, Blaas HG, Tegnander E, Torp SH. Comparison of prenatal ultrasound and postmortem findings in fetuses and infants with congenital heart defects. Ultrasound Obstet Gynecol 1999;13:117-26.

35. Akgun H, Basbug M, Ozgun MT, Canoz O, Tokat F, Murat N, Ozturk F. Correlation between prenatal ultrasound and fetal autopsy findings in fetal anomalies terminated in the second trimester. Prenat diagn 2007;27:457-62.

36. Gómez O, Martinez JM, Olivella A, Bennasar M., Crispi F, Masoller N, Bartrons J, Puerto B, Gratacós E. Isolated ventricular septal defects in the era of advanced fetal echocardiography: risk of chromosomal anomalies and spontaneous closure rate from diagnosis to age of 1 year. Ultrasound Obstet Gynecol 2014;43:65-71.

37. Durand I, Deverriere G, Thill C, Lety AS, Parrod C, David N, Barre E, Hazelzet T. Prenatal detection of coarctation of the aorta in a nonselected population: a prospective analysis of 10 years of experience. Pediatr cardiol 2015;36:1248-54.

38. Gómez O, Soveral I, Bennasar M, Crispi F, Masoller N, Marimon E, Bartrons J, Gratacós E, Martinez JM. Accuracy of fetal echocardiography in the differential diagnosis between truncus arteriosus and pulmonary atresia with ventricular septal defect. Fetal Diagn Ther 2016;39:90-9.

39. Hendler I, Blackwell SC, Bujold E, Treadwell MC, Wolfe HM, Sokol RJ, Sorokin Y. The impact of maternal obesity on midtrimester sonographic visualization of fetal cardiac and craniospinal structures. Int J Obesity 2004;28:1607.

40. Burton JL, Underwood J. Clinical, educational, and epidemiological value of autopsy. The Lancet 2007;369:1471-80.

41. Gordijn SJ, Erwich JJHM, Khong TY. Value of the perinatal autopsy: critique. Pediatr Devel Pathol 2002;5:480-8

42. Sebire NJ. Towards the minimally invasive autopsy? Ultrasound Obstet Gynecol 2006;28:865-7.

43. Thayyil S, Chitty LS, Robertson NJ, Taylor AM, Sebire NJ. Minimally invasive fetal postmortem examination using magnetic resonance imaging and computerised tomography: current evidence and practical issues. Prenat diagn 2010;30:713-18. 